\title{
Soil Organic Carbon Dynamics in Eroding and Depositional Landscapes
}

\author{
Kenneth R. Olson'1, Mahdi Al-Kaisi' ${ }^{2}$, Rattan Lal ${ }^{3}$, Larry Cihacek ${ }^{4}$ \\ ${ }^{1}$ Professor Emeritus, Department of NRES, College of ACES, University of Illinois, Champaign, IL, USA \\ ${ }^{2}$ Department of Agronomy, College of Agriculture, Iowa State University, Ames, IA, USA \\ ${ }^{3}$ School of Environment and Natural Resources, The Ohio State University, Columbus, OH, USA \\ ${ }^{4}$ School of Natural Resources Science, North Dakota State University, Fargo, ND, USA \\ Email:krolson@illinois.edu
}

How to cite this paper: Olson, K.R., AlKaisi, M., Lal, R. and Cihacek, L. (2016) Soil Organic Carbon Dynamics in Eroding and Depositional Landscapes. Open Journal or Soil Science, 6, 121-134. http://dx.doi.org/10.4236/ojss.2016.68013

Received: July 25, 2016

Accepted: August 28, 2016

Published: August 31, 2016

Copyright $\odot 2016$ by authors and Scientific Research Publishing Inc. This work is licensed under the Creative Commons Attribution International License (CC BY 4.0).

http://creativecommons.org/licenses/by/4.0/ (c) (i) Open Access

\begin{abstract}
As a requisite to determining management practice effects on stored soil organic carbon (SOC) stock in a landscape unit, the baseline SOC stock with depth must be determined and the land use, management practices and erosion-induced changes measured periodically or over a period of time. The SOC loss and additions due to soil erosion, transport and deposition must be accounted for or be quantified when determining the real impact of the management practices on net SOC stock over time. Quantifying the SOC loss due to erosion will help avoid over estimation of the management practice performances. Appropriate soil sampling designs and sampling procedures are needed to establish a SOC stock baseline and to monitor and verify new SOC storage or sequestration as a result of a management practice. The Dinesen Prairie landscape in western Iowa, USA was sampled to provide a SOC stock baseline and then the adjacent cropland was sampled to determine the past impact of land use change, management practices and erosion on SOC stock retention. After 100 to 150 years of farming, the entire cropland landscape retained only $49 \%$ of the baseline prairie SOC stock. Only the cropland toe-slope (TS) retained more SOC stock than the prairie TS as a result of the erosion, transport and deposition of SOC rich sediment on the TS.
\end{abstract}

\section{Keywords}

Soil Organic Carbon, Erosion, Monitoring

\section{Introduction}

The conversion of prairie and forest to cultivated cropland has decreased the land's capacity to produce and maintain the soil's original organic carbon (SOC) stocks and 
created a paradox in attempts to achieve sustainable agricultural intensification, human food security and ecosystem resilience [1], [2]. Soil degradation processes, including soil erosion, in cropping systems have affected SOC stocks and are limiting agricultural productivity. SOC stocks are critical to the production of food, fresh water, air quality, erosion prevention, nutrient cycling, and support of wildlife habitat. The degradation of soil can be a result of soil erosion, transport and deposition of soil sediments and loss of SOC stocks. Cihacek et al. [3] proposed using universal standards for methods and procedures for measuring and verifying SOC stored in a terrestrial system.

De Gruijter et al. [4] provided a comprehensive overview of monitoring land resources. These researchers describe the many and varied decisions that must be made in the design and implementation of a monitoring strategy. As prerequisite to demonstrating the stored SOC stock in a landscape unit, Chappell et al. [5] suggested measuring changes in SOC stock in a landscape unit (entire or part of a field) over a period of time. In this case, the measurements represent the net balance between the storage and loss of SOC caused by management practices [6] and the loss and addition due to soil erosion. The impact of soil erosion must be documented to determine (quantify) the real impact of the management practices on SOC stocks [7], [8]. When net removal of SOC by soil erosion exceeds net addition by management practices, no real SOC gain would be documented even when management practices proven to enhance SOC stocks are implemented [9], [10]. Quantifying SOC loss due to erosion can avoid overestimation of the management practice performances. Appropriate soil sampling designs and sampling procedures are needed to monitor and verify SOC net storage or sequestration [3], [11].

Areas of permanent vegetation near wind-eroding soils can capture substantial quantities of SOC containing sediments [12]. Direct deposition of fresh or aged plant materials occurs where the materials move along with soil sediments in wind erosion events, sliding across the soil surface until a leeward face of a drift is reached. At this point, the plant materials drop out of the wind stream and are buried within the sediment deposit enriching the SOC as the plant materials decompose at a later time. Soil erosion is caused by energy from water, wind, gravity and chemical reactions. However, water erosion, receives most attention because its after-effects are more noticeable, and it is linked to other negative outcomes, such as impacted water quality and loss of productivity that resonate with the general populations of the US through its link with food production and security. Transport of SOC and nutrients by wind-blown soil particles is of potential relevance to water quality [13].

Most soil sampling techniques use distance from the soil surface as a primary metric. The soil surface, however, is a reliable datum only for measurement of $\mathrm{C}$ concentration characteristics directly related to distance from the soil surface at the time of sampling especially when evaluating near surface soil samples [14]. Deep SOC in soil profiles differ between the tillage treatments and various land uses. Deeper sampling will not completely overcome a bias caused by bulk density variations and resultant change in soil surface elevation except when the SOC constituent is universally absent at lower 
depths. Equivalent soil mass (mass-depth) instead of linear depth can be used to correct for tillage and land use treatment differences in soil bulk density, allowing more precise and accurate quantitative comparison of SOC constituents [14], [15]. It is recommended to sample to a lower soils depth, where SOC concentration is negligible. In most soils SOC concentration is uniformly absent at depths ranging from 0.5 to $1.0 \mathrm{~m}$ [3]. The SOC data should be expressed on an equal soil mass per unit area to the appropriate depth where SOC concentration is absent. An example of such units would be $\mathrm{Mg} \cdot \mathrm{C} \cdot \mathrm{ha}^{-1}$ to a $1 \mathrm{~m}$ depth [16].

SOC losses can occur from land use change, water erosion, conventional tillage use, oxidation and mineralization of organic matter, disturbance during planting, and disturbance when fertilizers or manure injection take place. This loss can be offset by the SOC gains from plant and root growth and residue decomposition and returned to the humus or soil organic matter (SOM). Previously eroded soils with low SOC content were identified as having significant potential to sequester SOC [17]. Olson [18] studied previously eroded soils on $6 \%$ slopes with low SOC content in an attempt to quantify the amount and rates of SOC storage and retention as a result of a conversion to a NT system.

Pre-treatment SOC baseline of the landscape unit, tract, field or plot should be determined prior to the study [6]. No SOC sequestration can actually occur in a landscape unit if SOC level was higher at the start of the experiment than at the end of the study. A pre-treatment SOC baseline is essential in all landscape studies to determine the amount and rate of SOC sequestration, steady state or loss. A pre-treatment SOC baseline is needed when determining the amount and rate of SOC sequestration, storage, retention or loss, especially on sloping and eroding landscape units (Figure 1) with more intensive cropping rotations (more row crops and fewer years of forages) during the study than in the previous years.

The primary objective of this paper is to present strategies to evaluate changes in SOC stock in a landscape unit over a period of time. A prairie grassland landscape was selected and sampled to establish the SOC stock baseline and the adjacent cropland landscape SOC stock was measured with depth to determine the effects of land use change, management practices and erosion on SOC stock retention. The impact of soil erosion on SOC stocks must be documented to determine the true impact of management practices. In this study, we examine the SOC stock monitoring protocols and the impact of soil erosion, transport and deposition on SOC stocks. There is a great deal of variation in crop rotations and management practices among land uses and cropping systems. It is these variations which influence whether SOC is retained, enhanced, and potentially sequestered or the SOC stock is simply lost to the atmosphere and aquatic ecosystems. Soil degradation within intensified agricultural systems will deplete SOC stocks and nutrients and result in a decline in soil structure, loss of soil resilience as soil functions and services decline, a loss of soil, a loss of soil biodiversity, and disruption to key biotic and a biotic processes necessary for intensive cropping system productivity [19]. 


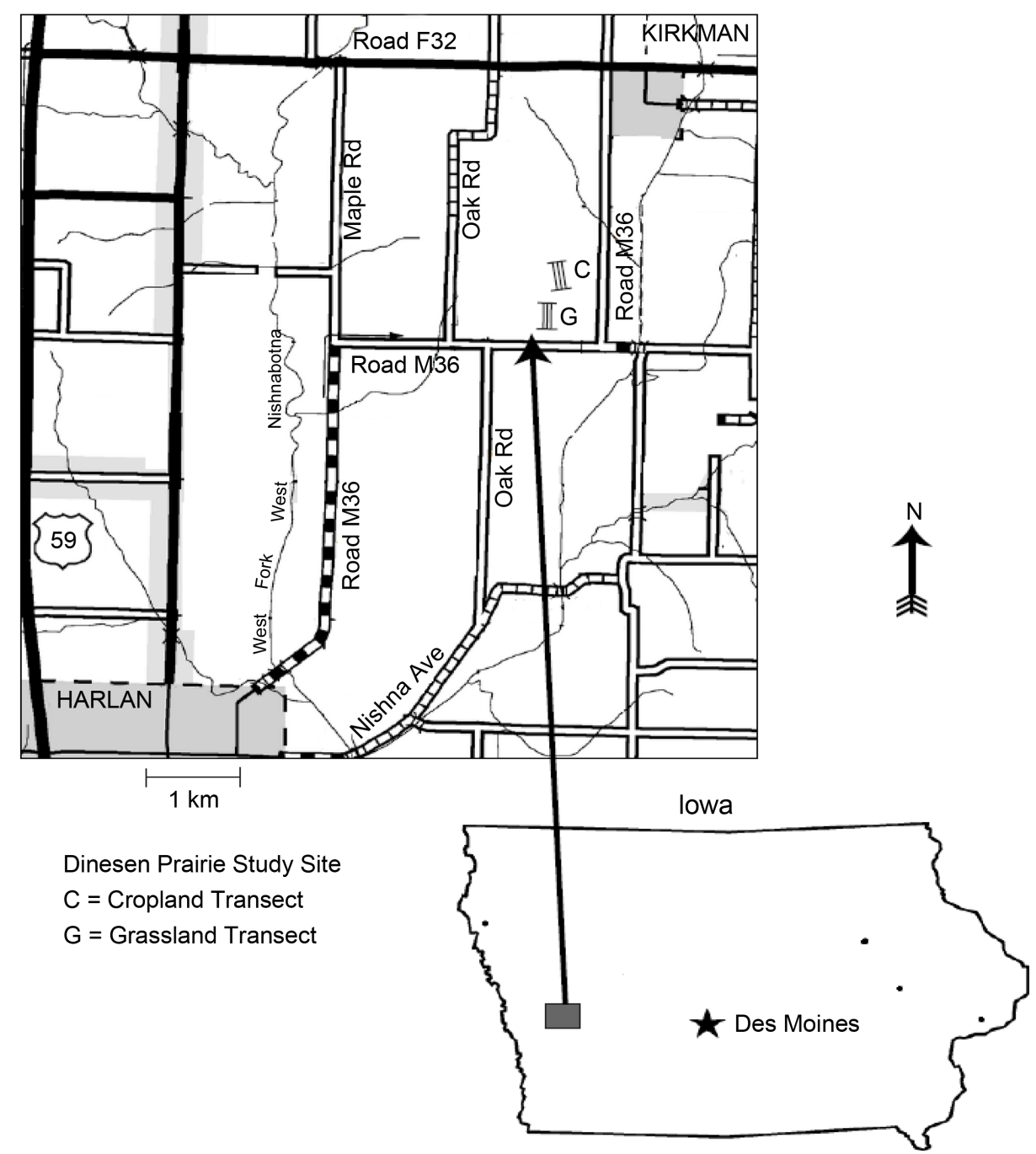

Figure 1. Map of the Dinesen Prairie study sites near Harlan in western Iowa (US) [2] (modified from Salemme 2015).

\section{Material and Methods}

\section{Site Description and Sampling Procedure}

The Dinesen Prairie study site is located in western Iowa near the city of Harlan [2] (Figure 1). The mean annual temperature for the area is 8.6 degrees $\mathrm{C}$ and the mean annual rainfall is $84.7 \mathrm{~cm}$. Two treatments were used, prairie and agriculture, both on sloping landscapes. A monument marker at the prairie site suggests the location has not been farmed since at least 1946 and also states that the area has never been plowed. However, the area was seeded with legumes at some point and is believed to have been used for grazing in the past. Presently, controlled burns are used to manage the prairie in years when weather permits and the area is generally mowed in the fall. In the crop plot a corn and soybean rotation and no-till management are used. The plots were located adjacently with a south facing aspect. The prairie plot is on Marshall silty clay loam with slopes ranging from $5 \%$ to $14 \%$. The summit of the crop plot is on Marshall 
silty clay loam but the majority of the catena is on Exira silty clay loam with slopes ranging from $5 \%$ to $14 \%$.

Soil bulk density samples (mass per unit volume) were collected from the same locations using a Model 200 Soil Core Sampler manufactured by Soil Moisture Equipment Corp. The inner dimensions of the sampling ring were $5.4 \mathrm{~cm}$ by $6 \mathrm{~cm}$. The soil bulk density samples (mass per unit volume) were oven-dried at 110 degrees $C$ for 48 hours prior to weighing for bulk density determination. SOC was determined using a modified version of the Walkley-Black wet oxidation method, procedure number 6A1 [20].

Statistical analysis was done using SAS version 9.4 [21]. T-tests were used to compare the different positions and depths of the two land-use treatments. The Wilcoxon rank sum test was used for any data that were not normally distributed. In all instances an alpha of 0.05 was used to declare significance.

Two treatments were used, prairie and cropland with both sides on sloping and eroding landscapes. The sampling scheme consisted of three parallel transects spaced $10 \mathrm{~m}$ apart and running up and down the slope from the summit (SU) to the TS. Transects for the prairie plots were $140 \mathrm{~m}$ in length while the adjacent crop transects were $130 \mathrm{~m}$. Each transect was sampled at the SU, SH, upper backslope (UBS), lower backslope (LBS), footslope (FS), and TS. Two soil cores were collected to a depth of $1 \mathrm{~m}$ at each landscape position on both land use treatments. Soil cores were divided into five intervals: $0-15 \mathrm{~cm}, 15-30 \mathrm{~cm}, 30-50 \mathrm{~cm}, 50$ to $75 \mathrm{~cm}$ and $75-100 \mathrm{~cm}$ for SOC stock measurements. Soil bulk density samples (mass per unit volume) were collected from the same locations and layers.

\section{Results}

The SOC stock for the prairie site was significantly higher than the cropland site for all landscape positions except for the TS (Table 1). The SOC mass was determined using bulk density data [2]. SOC stock was also weighted by landscape segment length to account for the different transect lengths when comparing the land use treatments. The UBS, LBS and FS of the cropland had the largest differences in SOC stock and averaged $73 \%$ less SOC than the prairie. The TS of the cropland showed a $9 \%$ increase in SOC stock over the grassland site reflecting the deposition of SOC rich sediments. The cropland at the Dinesen site retained $49 \%$ of the SOC in the landscape, and contained SOC stock in $1 \mathrm{~m}$ layer of soil at $230 \mathrm{Mg} \cdot \mathrm{C} / \mathrm{ha}$. Aland use change to cropland with erosion reduced the SOC stock in $1 \mathrm{~m}$ of soil to $114 \mathrm{Mg} \cdot \mathrm{C} / \mathrm{ha}$. Only the cropland TS retained 9\% more SOC stock than the prairie TS as a result of erosion of the upper landscape positions and deposit of SOC rich sediment on the TS. Based on high SOC stock in the 0.50 to $0.75 \mathrm{~m}$ and the 0.75 to $1.00 \mathrm{~m}$ layers [2] of the cropland TS, there would have been significantly more SOC stock in the 1.0 to $3.0 \mathrm{~m}$ layer. The cropland TS SOC stock was underreported as a result of protocol of sampling to a $1 \mathrm{~m}$ depth on all landscape positions to get a net SOC stock value for same depth for each land use treatment. The cropland adjacent to the Dinesen Prairie was only able to retain $49 \%$ of the SOC in the entire landscape to a $1 \mathrm{~m}$ depth. 
Table 1. SOC mass at Dinesen Prairie site by landscape segment weighted for segment length.

\begin{tabular}{|c|c|c|c|c|c|}
\hline & Mass of SOC & Landscape & Landscape & Weighed mass of SOC & Cropland \\
\hline Landscape & in $1 \mathrm{~m}$ layer & Segment & Segment \% & in Landscape Segment & impact on SOC \\
\hline Position & $\mathrm{Mg} \cdot \mathrm{C} / \mathrm{ha}$ & Length in $\mathrm{m}$ & of Transect & $\mathrm{Mg} \cdot \mathrm{C} / \mathrm{ha}$ & $\%$ \\
\hline \multicolumn{6}{|c|}{ Prairie Plots } \\
\hline Summit & $214 a$ & $26.7 \mathrm{a}$ & 0.15 & $32.6 \mathrm{a}$ & \\
\hline Shoulder & $218 \mathrm{a}$ & $30.6 \mathrm{a}$ & 0.17 & $38.0 \mathrm{a}$ & \\
\hline U. Backslope & $221 \mathrm{a}$ & $31.3 \mathrm{a}$ & 0.18 & $39.4 \mathrm{a}$ & \\
\hline L. Backslope & $242 \mathrm{a}$ & $26.1 \mathrm{a}$ & 0.15 & $36.1 \mathrm{a}$ & \\
\hline Footslope & $223 a$ & $27.2 \mathrm{a}$ & 0.16 & $34.7 \mathrm{a}$ & \\
\hline Toeslope & $261 \mathrm{a}$ & $33.4 \mathrm{a}$ & 0.19 & $49.8 \mathrm{a}$ & \\
\hline Total & $1379 a$ & $175 a$ & & $230 \mathrm{a}$ & \\
\hline \multicolumn{6}{|c|}{ Cropland Plots } \\
\hline Summit & $109 b$ & $22.9 \mathrm{a}$ & 0.14 & $14.8 \mathrm{~b}$ & -55 \\
\hline Shoulder & $99 \mathrm{~b}$ & $27 \mathrm{a}$ & 0.16 & $15.9 \mathrm{~b}$ & -58 \\
\hline U. Backslope & $58 \mathrm{~b}$ & $30 \mathrm{a}$ & 0.18 & $10.2 \mathrm{~b}$ & -74 \\
\hline L. Backslope & $35 b$ & $26.9 \mathrm{a}$ & 0.16 & $5.5 \mathrm{~b}$ & -85 \\
\hline Footslope & $85 \mathrm{~b}$ & $26.5 \mathrm{a}$ & 0.16 & $13.3 \mathrm{~b}$ & -62 \\
\hline Toeslope & $257 a$ & $35.8 \mathrm{a}$ & 0.21 & $54.4 \mathrm{~b}$ & 9 \\
\hline Total & $642 \mathrm{~b}$ & $169 a$ & & $114 \mathrm{~b}$ & -51 \\
\hline
\end{tabular}

Values with the same letter for the same landscape segment, same layer depth, and different land uses are not significantly different at the 0.05 probablility level.

\section{Discussion}

\subsection{Impact of Soil Erosion Processes on SOC Cycling and Accounting Models}

Landscape position affects the A horizon, root zone thicknesses and depth to the parent material. The A horizon and root zone were the thickest on the SU and TS. If one had sampled only the 20 -cm layer, the SOC located below that depth on the SU, SH, FS and TS (Figure 2) would not have been included. Landscape position affects original soil formation processes with thicker development on higher, drier positions and thicker development on the lower more moist positions. Landscape position also affects natural SOC levels. In addition, the root zone below the $20-\mathrm{cm}$ layer also contained significant SOC stock for all landscape positions [22], [23].

There are also erosion, transport and depositional effects on FS, TS and depressional sites through deposition of sediment and burial of topsoil, pollution by agrochemicals, inundation, and anaerobiosis leading to methanogenesis and nitrification/denitrification that lead to land degradation. An important strategy for sloping lands is to reduce risks of soil erosion and sedimentation by adoption of best management practices (BMPs) and reducing risks of soil erosion, transport and deposition. The outcomes of soil ero- 
sion are processes destructive to soil resilience and productivity, which are represented by SOC loss through increase in GHGs emissions [24], pollution of water, and contamination of coastal ecosystems by sedimentation and other non-point source pollutants (Figure 3) [25].

The redistribution and loss of soil through different pathways within eroding, depositional and landscape units and water bodies creates new soil conditions, where SOC-rich sediments are transported from the upper landscape to lower positions. This will create changes in soil hydrological conditions where low depressional areas can lead to both anaerobic conditions conducive to $\mathrm{N}_{2} \mathrm{O}$ and $\mathrm{CH}_{4}$ gas production and subsequent emissions while highly erodible uplands result with more oxidative potential for SOC and low productivity [26].

These changes in agricultural practices have been documented by several studies

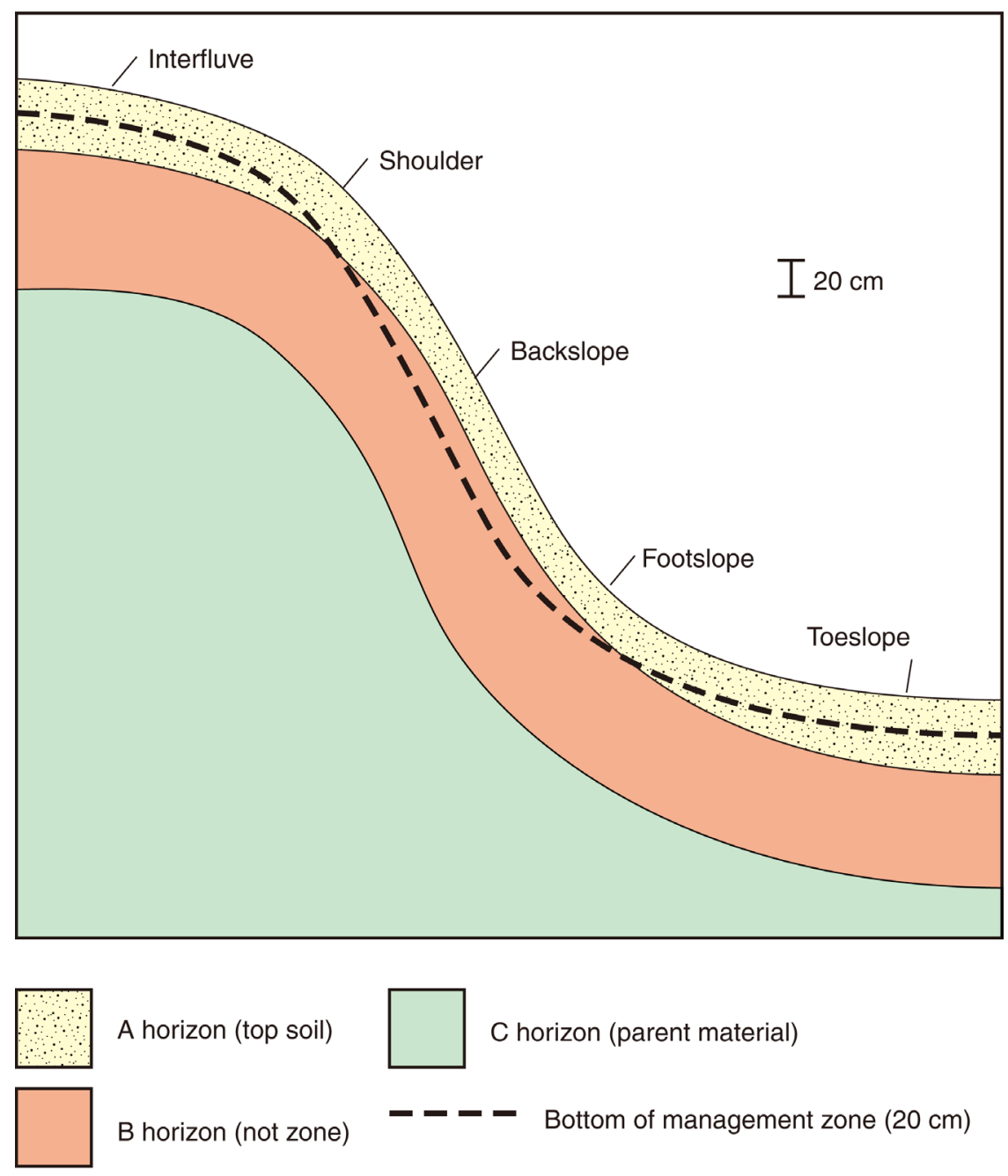

Legend

Figure 2. A horizon thickness, root zone thickness and depth to parent material is shown for a hillslope landscape [16] (modified from Olson and Al-Kaisi 2015). Published with copyright permission from Catena. 


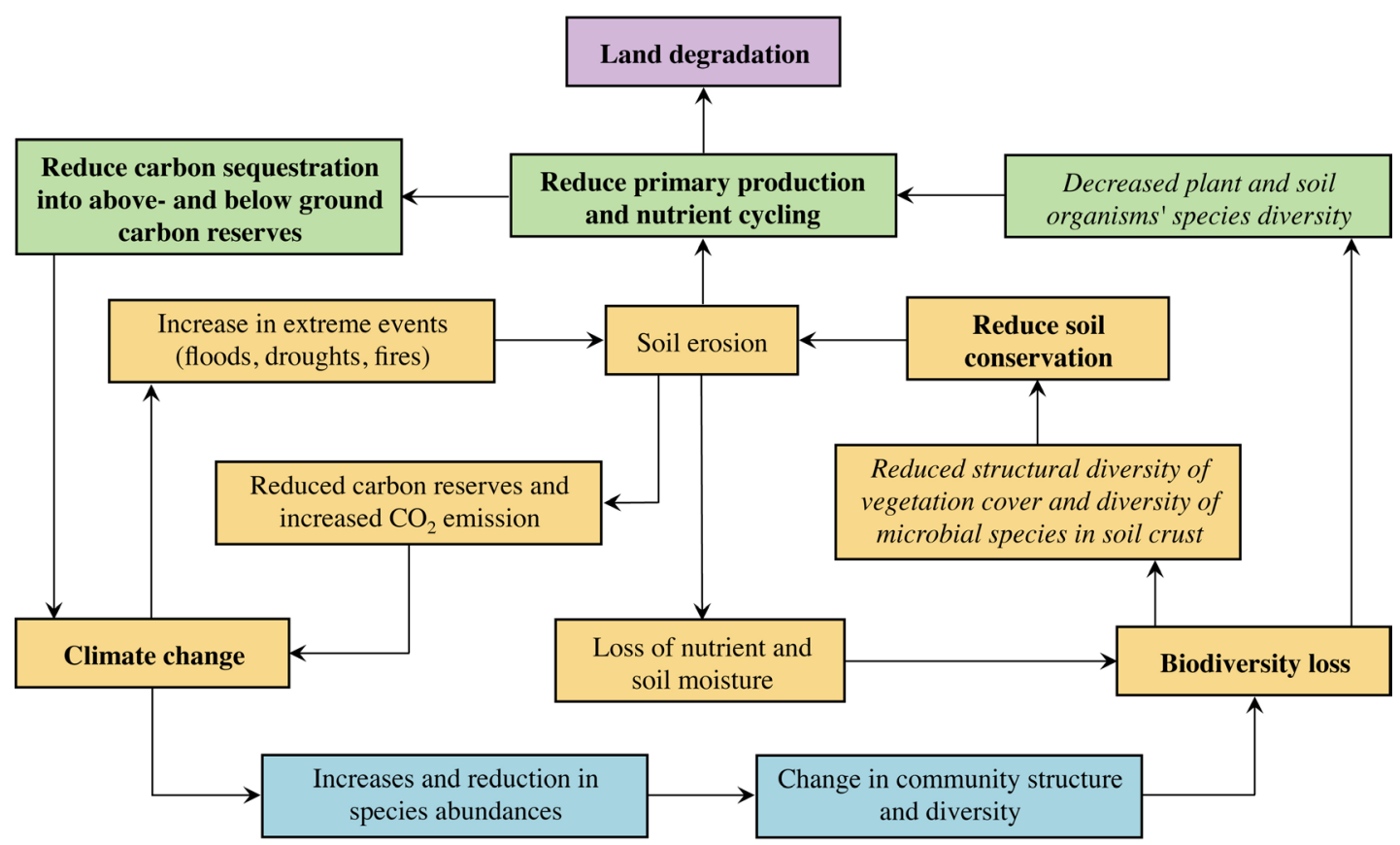

Figure 3. Major pathways by which biodiversity loss and other disservices from soil erosion occur [23] (modified from Lal et al. 2004).

[27]-[29] where land intensively cultivated is associated with medium to low agro-biodiversity due to the conversion of natural ecosystem to cropland and the increase of soil degradation as a result of soil erosion [30]. Figure 3 shows the major pathways by which biodiversity loss services from soil erosion can occur. An increase in land degradation, due to lack of conservation of natural resources and the increase in soil erosion leads to a reduction in SOC sequestration due to loss of primary productivity and biodiversity [29].

Chappell et al. [5] identified the common misconceptions used to justify and perpetuate the exclusion of soil erosion, transport and deposition by wind and water from $\mathrm{C}$ cycling and $\mathrm{C}$ accounting models. These included: 1) soil erosion is no longer a threat to food production and the environment; 2 ) soil erosion need not be measured because it is accounted for by landscape use and management practices; and 3) soil erosion can merely redistribute SOC in a field or landscape or deliver it to a stream or to the atmosphere. The fact remains that while soil erosion processes may be related to land use and management practices, it exacerbates soil degradation and loss of productivity. Therefore, it must be accounted for when monitoring a landscape unit for accurate assessment of soil $\mathrm{C}$ dynamics and the pathways that affect its fate. Soil erosion contribution to SOC stock loss is driven by management practices. This highlights the coupled nature of management practices and water and wind erosion processes that ultimately lead to permanent and significant loss of SOC stock (30\%) [17].

Wind erosion, dust transport and $\mathrm{CO}_{2}$ emission from cultivated fields are readily moved to great distances [12] and it is not uncommon for water erosion to remove soil from the terrestrial ecosystem to the ocean [5]. Water erosion removes soils on sloping 
land [31] and deposits material on floodplain bottomlands or in the ocean. Olson et al. [32] showed that nearly level $(<1 \%)$ upland plots were subject to erosion, transport and deposition of SOC-rich sediments. Even small amounts of soil erosion can make a significant difference to the SOC stock change over time because the eroded material has higher ER (enrichment ratio) and is typically considered to be enriched relative to the soils from which the material has been removed [5], [18], [31], [32]. Because soil erosion is highly variable in space and time, it must be monitored or measured at the same time as SOC stock is measured. Otherwise, it will not be possible to unequivocally demonstrate that measured changes in SOC stocks can be attributed to land use and management practices alone.

Chappell et al. [5] reported changes in SOC stocks over time using simulation models as the difference between outputs of $\mathrm{C}$ and losses due to decomposition process of existing SOC stocks with rate modifiers applied to an intrinsic decay constant. Chappell and colleagues found that erosion of topsoil changed the composition and structure of the soil at the eroded location. Sediment deposition on soil from elsewhere can modify the soil micro-environment (i.e., temperature change, hydrology, SOC decomposition rates, etc.). This makes a strong case that erosion should be included in $\mathrm{C}$ cycling and $\mathrm{C}$ accounting models [33]-[36].

Sometimes, a slow rate of erosion leads to soil formation and creation of fertile alluvial plains. When accelerated by anthropogenic activity, erosion becomes a destructive process with numerous adverse on-site and off-site effects (Figure 3). Among on-site effects is a decline in the soil quality of eroded land and reduction in agronomic productivity and decrease in plant nutrient availability [37] and water use efficiency [38]. With erosion being a selective process, soil subjected to accelerated erosion is regressively depleted of its topsoil, SOC (concentration and stock) and nutrient reserves. Decline in the root depth zone and reduction in available water capacity (AWC) increase the susceptibility of crops grown on eroded soils to pedologic and agronomic droughts [39].

\subsection{SOC Stock Measuring Challenges in Eroded Landscapes}

Soil erosion causes SOC redistribution within terrestrial ecosystems, to the atmosphere and oceans. Li et al. [40] and Chappell et al. [5] reported that dust export is an essential component of the SOC and carbon dioxide $\left(\mathrm{CO}_{2}\right)$ budget because wind erosion contributes to the $\mathrm{C}$ cycle by selectively removing SOC from vast areas of Australia and transporting $\mathrm{C}$ dust quickly offshore and augmenting the net loss of $\mathrm{C}$ from terrestrial systems. Li et al. [40] found reduced SOC erosion and/or SOC dust accumulation by vegetation-cover crop must be induced by changes in land use and management practices. Li et al. [40] reported that $\mathrm{C}$ sequestration resulted from a reduction of $\mathrm{C}$ erosion and dust-C trapped by vegetation-cover crop. Chappell et al. [35] mapped net (1950s1990) SOC redistribution across Australia and estimated that water and wind erosion represent $2 \%$ of total C stock in the $0-10 \mathrm{~cm}$ soil layer. Soil erosion is not explicitly included in Australian national SOC stock accounting, which renders estimates of $\mathrm{CO}_{2}$ 
flux from soils highly uncertain. The inclusion of an erosion component may reduce that uncertainty [34], [36], [41] and improve the accuracy for the reporting of GHG emissions. Measuring wind-eroded SOC in the dust cycle is therefore essential to quantify the release of $\mathrm{CO}_{2}$ from SOC dust to the atmosphere and the contribution of SOC deposition to downwind $\mathrm{C}$ depositional sites.

Measuring SOC stocks change across a land unit, such as eroding, depositional or landscape units with different land use practices require sufficient soil samples within each landscape unit to ensure that individual temporal and spatial SOC changes are representative of the entire land unit [5], [36]. If insufficient soil samples are taken, it is unlikely that the measured values of SOC will be representative of the landscape unit spatially and may lead to greater variability.

If variance in measured SOC stocks at the first sampling period is larger than that in the second sampling period, it will be difficult to assess change in SOC stocks over the land unit [4], [5]. Analytical methods changes or measurements by different laboratories can affect variability. Setting up and implementing a sampling design can be a challenge when little information is available on the variability of SOC within the land unit. Consequently, it is difficult to establish what type of sampling design to use and how many samples to take in each sampling round [9], [10]. Therefore, a consistent and standardized protocol should be followed each time samples are collected to minimize variability due to sampling protocol within each sampling time or period.

Chappell et al. [5] produced a technical document based on literature and defined the statistical justifications for recommendation of SOC monitoring in a landscape unit. The three distinct phases included: 1) setup sampling design and the assumptions/decisions necessary for implementation to determine magnitude of a detectable change in SOC over time and at an acceptable cost, 2) modify the sampling design after measurements of SOC are made in the first round of sampling (i.e., more or less SOC variance than expected), and 3) determine the actual detectable change in SOC by comparing SOC measurement from the first round of sampling with the second round of sampling (e.g., 5 years later) using a mean difference or other analytical test.

De Gruijter et al. [4] and Chappell et al. [5] restricted their consideration of sampling designs and their use over time to the most basic and easily adopted approaches. There is an expected variation in SOC if the approaches are formed from a series of decisions that were used to estimate the minimum detectable change (MDC). Assuming that spatial and temporal variations occur in land unit, the likely measurement error associated with quantifying SOC can affect the confidence in the results. Chappell et al. [5] estimated the variance of the detectable mean change in SOC. The procedure should help address spatial variability as a basis for detecting temporal changes. One approach to reduce variability over time is to use a system of geo-referencing sampling points which remain constant on the landscape regardless of changes in land use or management [3].

The final assumption by of this methodology relates to variability of SOC with depth [5]. The SOC stocks typically decline with increasing soil depth. However, this is not always the case. Variation of SOC across a land unit is most likely to be the largest in 
the surface soil layer which has the largest SOC stock depending on soil bulk density. Benefits of a sampling design that reduces the number of samples for the greatest depth can be outweighed by the need to visit more locations to collect samples near the soil surface. When sampling soil, it is typical to collect soil samples from all layers at the same time. Since the surface layer is usually the most variable in SOC stocks, a soil sampling protocol design for this layer should be adequate for collecting soil at depths where SOC is less variable.

\section{Conclusions}

A landscape soil sampling protocol was developed to establish the native prairie baseline SOC stock $(230 \mathrm{Mg} \cdot \mathrm{C} / \mathrm{ha})$ to a $1 \mathrm{~m}$ depth for the entire native prairie landscape. The cropland SOC stock was determined for each landscape position and the entire landscape to determine cropland retention of SOC stock (114 Mg.C/ha). The cropland landscape adjacent to Dinesen Prairie had less SOC stock than the baseline prairie landscape except for the TS which retained 109\% of the SOC stock in the upper $1 \mathrm{~m}$ as a result of erosion from the upper landscape positions and the deposition of SOC rich sediment on the TS. For the entire landscape the cropland retained only $49 \%$ of the baseline prairie SOC stock.

If the intention of monitoring SOC stocks is to detect change and attribute the change to a particular land management practice/use then samples must be obtained over the entire landscape unit (area upon which the management practice is applied). In this case mean change and its variability determine level of detectability of such change. Consequently, this will dictate the intensity of soil sampling across the landscape unit to determine SOC stocks at different locations. When implementing, attention must be paid to the processes which maintain and form SOC stocks to ensure soil productivity and reduce the degradation processes, such as erosion, which drive SOC depletion. These processes are influenced by both natural and anthropogenic drivers. Soil erosion should be viewed as SOC redistribution not only across landscape, but also in the larger context of impacts on soil function and ecosystem sustainability and services and disservices. Appropriate soil sampling designs and sampling procedures are needed to determine SOC change and verify SOC net storage or sequestration. Quantifying the SOC loss due to erosion will help avoid over estimation of the management practices on net SOC stock over time.

\section{Acknowledgements}

Published with the approval of the Director of the Office of Research at the University of Illinois, Urbana, IL. Funded as part of Regional Research Project 367 and in cooperation with North Central Regional Project NC-1178 (Soil Carbon Sequestration).

\section{References}

[1] Biggs, R., Schluter, M., Biggs, D., Bohensky, E.L., BurnSilver, S., Cundill, G., Dakos, V., Daw, T.M., Evans, L.S., Kotschy, K., Leitch, A.M., Meek, C., Quinlan, A., Raudsepp-Hearne, C., Robards, M.D., Schoon, M.L., Schultz, L. and West, P.C. (2012) Toward Principles of 
Enhancing the Resilience of Ecosystem Services. Annual Review of Environment and Resources, 37, 421-48. http://dx.doi.org/10.1146/annurev-environ-051211-123836

[2] Salemme, R. (2015) Land-Use Change Effects on Soil Organic Carbon, Total Soil Nitrogen, and Soil Erosion in a Temperate Forest and Grassland. Thesis, Graduate College of University of Illinois at Urbana-Champaign, Urbana, IL.

[3] Cihacek, L.J., Botnen, B.W. and Steadman, E.N. (2010) A Sampling Protocol for Monitoring, Measurement, and Verification of Terrestrial Carbon Sequestration in Soils. Plains $\mathrm{CO}_{2}$ Reduction (PCOR) Partnership Value-Added Report, Energy and Environment Research Center, University of North Dakota, Grand Forks, ND, 9 p.

[4] De Gruijter, J.J., Brus, D.J., Bierkens, M.F.P. and Knotters, M. (2006) Sampling for Natural Resource Monitoring. Springer, Berlin, Heidelberg, New York.

http://dx.doi.org/10.1007/3-540-33161-1

[5] Chappell, A., Baldock, J. and Rossel, R.V. (2013) Sampling Soil Organic Carbon to Detect Change over Time. CSIRO Sustainable Agricultural Flagship, Department of the Environment, Australian Government, 39 p.

[6] Olson, K.R., Al-Kaisi., M.M., Lal, R. and Lowery, B. (2014) Experimental Consideration, Treatments, and Methods in Determining Soil Organic Carbon Sequestration Rates. Soil Science Society of America Journal, 78, 348-360. http://dx.doi.org/10.2136/sssaj2013.09.0412

[7] Olson, K.R., Gennadiyev, A.N., Zhidkin, A.P. and Markelov, M.V. (2012) Impact of Land Usechange, Slope and Erosion on Soil Organic Carbon Retention and Storage USA. Soil Science, 177, 269-278. http://dx.doi.org/10.2136/sssaj2013.09.0412

[8] Olson, K.R. (2013) Soil Organic Carbon Sequestration in U.S. Cropland: Protocol Development. Geoderma, 195-196, 201-206. http://dx.doi.org/10.1016/j.geoderma.2012.12.004

[9] Allen, D.E., Pingle, M.J., Page, K.L. and Dalal, R.C. (2010) A Review of Sampling Designs for the Measurement of Soil Organic Carbon in Australian Grazing Lands. The Rangeland Journal, 32, 227-246. http://dx.doi.org/10.1071/RJ09043

[10] Bishop, T.F.A. and Pringle, M.J. (2012) Paddock-Scale Soil Carbon Inventory and Monitoring: A Meta-Analysis for Sample Size Requirements. Proceedings of the Soil Science Conference, Hobart, Tasmania.

[11] Olson, K.R., Al-Kaisi, M.A., Lal, R. and Cihacek, L.J. (2016) Landscape, Soil Erosion, Land use and Plot Design Considerations When Measuring Soil Organic Carbon Stocks. Journal of Soil and Water Conservation, 71, 61A-67A. http://dx.doi.org/10.2489/jswc.71.3.61A

[12] Cihacek, L.J. and Ulmer, M.G. (1995) Estimated Soil Organic Carbon Losses from LongTerm Crop-Fallow in Northern Great Plains of USA. In: Lal, R., Kimble, J., Levine, E. and Steward, B.A., Eds., Soil Management and Greenhouse Effect, Lewis Publishers, Boca Raton, Florida, 85-92.

[13] Cihacek, L.J., Sweeney, M.D. and Deibert, E.J. (1992) Characterization of Wind Erosion Sediments in the Red River Valley of North Dakota. Journal of Environmental Quality, 22, 305-310. http://dx.doi.org/10.2134/jeq1993.00472425002200020011x

[14] Wuest, S.B. (2009) Correction of Bulk Density and Sampling Methods Biases Using Soil Mass per Unit Area. Soil Science Society of America Journal, 73, 312-316. http://dx.doi.org/10.2136/sssaj2008.0063

[15] Lee, J., Hopmans, J.W., Rolston, D.E., Baer, S.G. and Six, J. (2009) Determining Soil Carbon Stock Changes: Simple Bulk Density Corrections Fail. Agriculture, Ecosystems, and Environment, 134, 251-256. http://dx.doi.org/10.1016/j.agee.2009.07.006

[16] Olson, K.R. and Al-Kaisi, M.M. (2015) Impact of Soil Sampling Depth on Soil Organic 
Carbon Sequestration, Storage, Retention and Loss. Catena, 125, 33-37. http://dx.doi.org/10.1016/j.catena.2014.10.004

[17] Lal, R., Kimble, J.M., Follett, R.F. and Cole, C.V. (1998) The Potential of US Cropland to Sequesters Carbon and Mitigate the Greenhouse Effect. Sleeping Bear Press Inc., Ann Arbor Press, Chelsea, 128 p.

[18] Olson, K.R. (2010) Impacts of Tillage, Slope and Erosion on Soil Organic Carbon Retention. Soil Science, 175, 562-567. http://dx.doi.org/10.1097/SS.0b013e3181fa2837

[19] Lal, R. (2015) Sustainable Intensification for Adaptation and Mitigation of Climate Change and Advancement of Food Security in Africa. In: Lal, R., Singh, B.R., Mwaseba, D.L., Kraybill, D., Hansen, D.O. and Eik, L.O., Eds., Sustainable Intensification to Advance Food Security and Enhance Climate Resilience in Africa, Chapter 1, Springer, Berlin, 3-17. http://dx.doi.org/10.1007/978-3-319-09360-4_1

[20] Soil Survey Staff (2004) Soil Survey Laboratory Methods Manual. Soil Survey Investigations Report No. 42 Version 4.0, United States Department of Agriculture, Natural Resources Conservation Service, Nebraska.

[21] SAS Institute (2015) SAS/STAT Guide for Personal Computers. Version 9.4., SAS Institute, Cary.

[22] Kreznor, W.R., Olson, K.R. and Johnson D.L. (1992) Field Evaluation of Methods to Estimate Soil Erosion. Soil Science, 153, 69-81. http://dx.doi.org/10.1097/00010694-199201000-00010

[23] Kreznor, W.R., Olson, K.R., Johnson, D.L. and Jones, R.L. (1990) Quantification of PostSettlement Deposition in a Northwestern Illinois Sediment Basin. Soil Science Society of America Journal, 54, 1393-1401. http://dx.doi.org/10.2136/sssaj1990.03615995005400050031x

[24] Olson, K.R., Gennadiyev, A.N., Zhidkin, A.P. and Markelov, M.V. (2011) Impact of Land Use Change and Soil Erosion in Upper Mississippi River Valley on Soil Organic Carbon Retention and Greenhouse Gas Emissions. Soil Science, 176, 449-458. http://dx.doi.org/10.1097/SS.0b013e3182285cde

[25] Lal, R., Griffin, M., Apt, J., Lave, L. and Morgan, G. (2004) Response to Comments on "Managing Soil Carbon". Science, 305, 1567. http://dx.doi.org/10.1126/science.1101271

[26] Lal, R. (2003) Soil Erosion and the Global Carbon Budget. Environmental International, 29, 437-450. http://dx.doi.org/10.1016/S0160-4120(02)00192-7

[27] Thrupp, L.A. (2000) Linking Agricultural Biodiversity and Food Security: The Valuable Role of Agrobiodiversity for Sustainable Agriculture. International Affairs, 76, 265-281. http://dx.doi.org/10.1111/1468-2346.00133

[28] Mooney, H.A., Cooper, A. and Reid, W. (2005) Confronting the Human Dilemma. Science, 434, 561-562. http://dx.doi.org/10.1038/434561a

[29] MEA (2005) Ecosystems and Human Well-Being: Biodiversity Synthesis. World Resources Institute, Washington DC.

[30] Hadgu, K.M., Rossing, W.A., Kooistra, L. and van Bruggen, A.H. (2009) Sapatial Variation in Biodiversity, Soil Degradation and Productivity in Agricultural Landscapes in the Highlands of Tigray, Northern ETHIOPIA. Food Security, 1, 83-97. http://dx.doi.org/10.1007/s12571-008-0008-5

[31] Loughran, R.J., Elliott, G.L., McFarlane, D.J. and Campbell, B.L. (2004) A Survey of Soil Erosion in Australia Using Caesium-137. Australian Geographical Studies, 42, 221-233. http://dx.doi.org/10.1111/j.1467-8470.2004.00261.x

[32] Olson, K.R., Gennadiyev, A.N., Kovach, R.G. and Lang, J.M. (2013) The Use of Fly Ash to 
Determine the Extent of Sediment Transport on Nearly Level Western Illinois Landscapes. Soil Science, 178, 24-28. http://dx.doi.org/10.1097/SS.0b013e318284b5cd

[33] Kuhn, N.J., Hoffman, T., Schwenghart, W. and Dotterwerch, M. (2009) Agricultural Soil Erosion and Global Carbon Cycle: Controversy Over. Earth Surface Processes and Landforms, 34, 1033-1038. http://dx.doi.org/10.1002/esp.1796

[34] Chappell, A., Webb, N.P., Viscara Rossel, R.A. and Bui, E. (2014) Australian Net (1950s1990) Soil Organic Carbon Erosion: Implications for $\mathrm{CO}_{2}$ Emission and Land-At- mosphere Modeling. Biogeosciences, 11, 5235-5244. http://dx.doi.org/10.5194/bg-11-5235-2014

[35] Chappell, A.J. Thomas, S.M., Read, A. and Leslie, C. (2012) The Dynamic of Soil Redistribution and Implications for Soil Organic Carbon Accounting in Agricultural South-Eastern Australia. Global Change Biology, 18, 2081-2088.

http://dx.doi.org/10.1111/j.1365-2486.2012.02682.x

[36] Chappell, A., Baldock, J. and Sanderman, J. (2016) The Global Significance of Omitting Soil Erosion from Soil Organic Carbon Cycling Schemes. Nature Climate Change, 6, 187-191.

[37] Nizeyimana, E. and Olson, K.R. (1988) Chemical, Mineralogical and Physical Differences between Moderately and Severely Eroded Illinois Soils. Soil Science Society of America Journal, 52, 1740-1748. http://dx.doi.org/10.2136/sssaj1988.03615995005200060041x

[38] Fenton, T.E., Kazemi, M. and Lauterbach-Barrett, M.A. (2005) Erosional Impact on Organic Matter Content and Productivity of Selected Iowa Soils. Soil \& Tillage Research, 81, 163 171. http://dx.doi.org/10.1016/j.still.2004.09.005

[39] Er Raji, M. and Cihacek, L.J. (1994) Erosion Effects on Selected Agronomic Parameters of Hard Red Spring Wheat across a Landscape. North Dakota Farm Research, 50, 26-29.

[40] Li, Y., Yu, H., Chappell, A., Zhou, N. and Funk, R. (2014) How Much Soil Organic Carbon Sequestration Is Due to Conservation Agriculture Reducing Soil Erosion. Soil Research, 52, 717-726. http://dx.doi.org/10.1071/SR14078

[41] Sanderman, J. and Chappell, A. (2012) Uncertainty in Soil Carbon Accounting Due to Unrecognized Soil Erosion. Global Change Biology, 19, 264-272.

http://dx.doi.org/10.1111/gcb.12030

Submit or recommend next manuscript to SCIRP and we will provide best service for you:

Accepting pre-submission inquiries through Email, Facebook, LinkedIn, Twitter, etc. A wide selection of journals (inclusive of 9 subjects, more than 200 journals)

Providing 24-hour high-quality service

User-friendly online submission system

Fair and swift peer-review system

Efficient typesetting and proofreading procedure

Display of the result of downloads and visits, as well as the number of cited articles

Maximum dissemination of your research work

Submit your manuscript at: http://papersubmission.scirp.org/

Orcontact ojss@scirp.org 